\title{
A new non-uniform blast load model for SDOF method of one-way reinforced concrete slab
}

\author{
W. Wang, D. Zhang, F. Lu, S.-C. Wang, and F. Tang \\ Institute of Technique Physics, College of Science, National University of Defense Technology, Changsha, \\ Hunan 410073, P.R. China
}

\begin{abstract}
A new effective model for calculation of the equivalent uniform blast load for non-uniform blast load such as close-in explosion of a one-way square and rectangle reinforced concrete slab is proposed in this paper. The model is then validated using single degree of freedom (SDOF) system with the experiments and blast tests for square slabs and rectangle slabs. Test results showed that the model is accurate in predicting the explosive charge weight and stand-off distance to impose a given damage level on the tested RC slabs especially for close-in blast load. It is shown that the new model is more accurate than the conventional $\mathrm{SDOF}$ analysis and is running faster than the FE analysis.
\end{abstract}

\section{Introduction}

Reinforced concrete slabs are typically analyzed for blast loadings using one of two methods of very different complexity: (2) finite element analysis methods (e.g., [1,2]); and (1) equivalent single degree of freedom (SDOF) analysis $[3,4]$. SDOF methods are common nowadays for blast design of protective structural elements $[4,8]$. This is the case even as many other powerful finite element methods have been developed in the last decades. The SDOF model is widely used in design because it presents several advantages such as ease of use and low running time, which have made it appealing for blast design and incorporation into design manuals $[9,11]$ for the blast analysis and design of building components. However, conventional SDOF analysis is incapable of capturing a spatially and temporally varying distribution of blast loading, cannot allow for variations of mechanical properties of the cross-section along the member, cannot simultaneously accommodate shear and flexural deformations, can only address strain rate effects indirectly, and can produce very conservative answers. A finite element analysis using codes such as LSDYNA [12] and AUTODYN [13] can be applied to analyze the structural response to blast loads but such an analysis is rarely used because of its perceived complexity and time consuming.

In this paper, a new effective SDOF method for calculation of the equivalent uniform blast load for nonuniform blast load is described herein. The proposed method captures key attributes of the non-uniform loading on the square reinforced concrete slab but retains much of the simplicity associated with equivalent SDOF analysis. The accuracy of the proposed method is validated using data from field blast testing of rectangle slabs. This paper presents key analytical and experimental results that can substantiate this main conclusion.

\section{Conventional SDOF method under blast loading}

The SDOF system for modeling the flexural response is based on Biggs [3], where the deflected shape of the structure is assumed to be the same as that resulting from the static application of the dynamic load. This is illustrated in Fig. 1. The equivalent mass and stiffness parameters are derived based on the mass density, Young's modulus, moment inertia, span length and boundary condition of the slab, as well as the deflection shape of the slab under uniform distributed static load. More details can be found in Biggs [3]. The simplification for flexural response has been widely accepted and recommended in Protective design manuals [9-11]. With effective factors, such SDOF system can give out maximum displacement, velocity and acceleration quickly. Consequently damage assessment can be carried out based on the maximum displacement of the structure or elements.

Upon transforming the structural slab into its equivalent flexural SDOF system, the governing differential equation of motion is presented as follows [14]:

$$
\ddot{x}(t)+2 \xi \omega^{\prime} \dot{x}(t)+\frac{R}{M_{e}}=\frac{P_{e}(t)}{M_{e}}
$$

in which $x(t), \dot{x}(t)$, and $\ddot{x}(t)$ are the flexural displacement, velocity, and acceleration, respectively, $M_{e}$ is the equivalent mass of the system, $R$ is the flexural dynamic resistance function, $\omega^{\prime}$ the flexural damped natural circular frequency, $\xi$ the flexural damping ratio, and $P_{e}(t)$ is the equivalent forcing function. The nonlinear equation is solved numerically using the Newmark $\beta$ method. The US Army uses the minimum value between $10 \%$ of the natural period and $3 \%$ of triangle positive loading duration as time step to solve an inelastic SDOF model [10]. In this study, the time step was $0.1 \%$ of smallest value of natural periods and positive loading duration, which is compared to US Army approach.

The flexural resistance function $R(x)$ of concrete structures under blast load is highly nonlinear. In this paper the function of structures is assumed to be elastic-perfectly plastic and tri-linear resistance functions for simple support slab and fixed support slab respectively and the slope of the unloading path is the same as that of loading path [10], as shown in Fig. 2. More details can be found in the protective design manuals [10]. The strain rate effect on flexural resistance is accounted for by the use of 


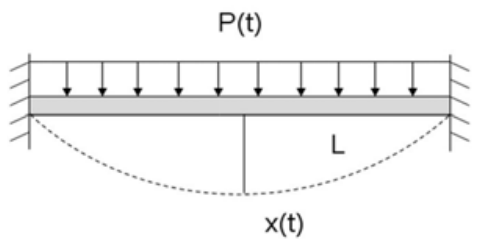

(a)

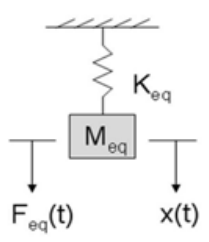

(b)
Fig. 1. Equivalent Spring-Mass SODF System (a) Slab load by blast (b) Equivalent SDOF.

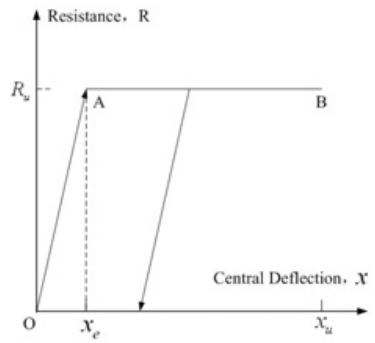

(a)

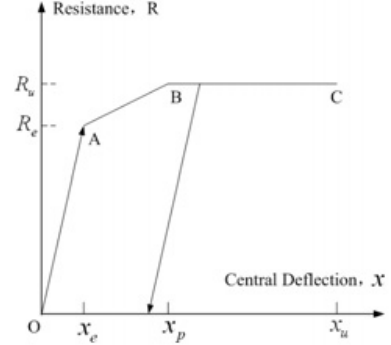

(b)
Fig. 2. Nonlinear resistance functions and their idealization of reinforced concrete slab (a) elastic-perfectly plastic and (b) Tri linear.

dynamically enhanced material strengths with a constant strain rate of $100 / \mathrm{s}$ which is mentioned in Low [15]. This is acceptable as shown by Krauthammer and his coauthors [16] that a constant strain rate with a reasonable order of magnitude is sufficient to yield good results.

\section{Equivalent uniform blast load}

As shown in [10], it can be very difficult to model component response to blast loads with complex spatial load distributions using a conventional SDOF analysis. Blast loads that vary significantly over the area of a structural component, such as close-in explosions, must be converted into an "equivalent" blast load that is spatially uniform over the whole area of the component at each time step because the load factor in SDOF analyses almost always assumes spatially uniform loading.

In this section an "equivalent" blast load is computed based on equating the external virtual work done by the equivalent uniform blast load to the external virtual work done by the non-uniform blast load such as closein explosions. Although Lu B and Silva PF [5,6] studied a procedure to convert dynamic point loads into uniform blast pressure, they did not consider the transformation of the non-uniform distributed blast load into uniform blast pressure. In this paper, the transformation of the nonuniform distributed blast load into uniform blast pressure is studied for SDOF analysis by the same external virtual work done.

A simply supported reinforced concrete slab is model here to study the equivalent load shown in Fig. 3. From Fig. 3, one can find that the blast pressure on the reinforced concrete slab is non-uniform for a close-in explosion. The

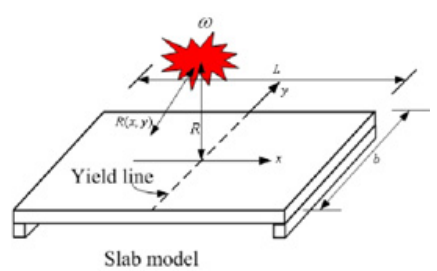

(a)

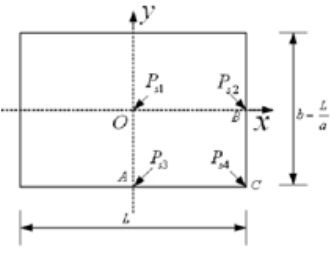

(b)
Fig. 3. Failure mechanism of a simply supported square reinforced concrete slab (a) Slab model under close-in explosion and (b) Platform of the slab.

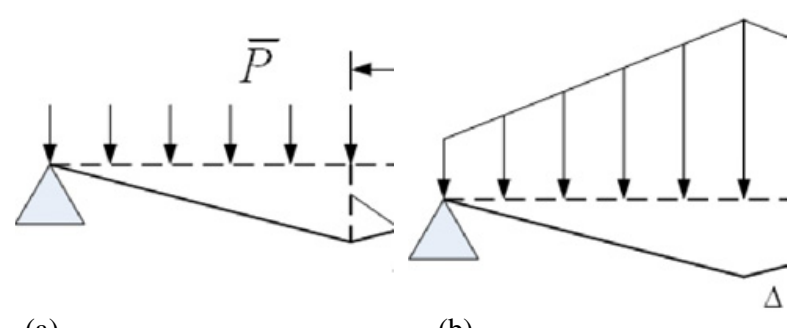

(a)

(b)

Fig. 4. Failure mechanism of a simply supported square reinforced concrete slab (a) Virtual work by uniform load and (b) Virtual work by blast pressure load.

pressure wave is significantly higher at the center of the slabs and dissipates rapidly towards the ends of the slab shown in Fig. 3(a). The peak pressure of the edge B is noted as $P_{s 2}$, the peak pressure of the edge $\mathrm{A}$ is noted as $P_{s 3}$, and the peak pressure of the corner C is noted as $P_{s 4}$ which is shown in Fig. 3 (b).

The failure model of the square slab is on the assumption of flexural failure in center yield line for the blast load and equivalent uniform blast load which is shown in Fig. 4.

Assuming symmetric load and deflection distributions, the support rotation $\theta$ is defined by the ratio of the calculated peak deflection to half a span length for one-way slabs:

$$
\tan \theta=\frac{2 \Delta}{L}
$$

where $L$ is span length of the element, and $\Delta$ is the max displacement of the center. Since $\theta$ is small enough, $\tan \theta$ approximately equals to $\theta$. Then $\Delta$ can be expressed as

$$
\Delta=\frac{\theta L}{2}
$$

The peak pressure function $P(x, y)$ is the assumed shape of the blast pressure wave and is developed by using the blast pressure waves presented in Fig. 4. In this paper, $P(x, y)$ can be simply expressed as

$$
\begin{aligned}
P(x, y)= & P_{s 1}+\frac{2}{L}\left(P_{s 2}-P_{s 1}\right) x+\frac{2 a}{L}\left(P_{s 3}-P_{s 1}\right) y \\
& +\frac{4 a}{L^{2}} x y\left(P_{s 4}-P_{s 2}-P_{s 3}+P_{s 1}\right) \\
& \times 0 \leq x \leq L / 20,0 \leq y \leq L /(2 a)
\end{aligned}
$$

where $P_{s 1}, P_{s 2}, P_{s 3}$ and $P_{s 4}$ are either by using the measured pressure in experiments or computed by current 
Table 1. Experimental air blast program of rectangle slabs.

\begin{tabular}{|c|c|c|c|c|c|c|}
\hline Blast & $\begin{array}{c}\text { Slab } \\
\text { name }\end{array}$ & $\begin{array}{c}\text { Dimension } \\
(\mathrm{mm})\end{array}$ & $\begin{array}{c}\text { Reinforcement } \\
\text { ratio(\%) }\end{array}$ & $\begin{array}{c}\text { Standoff } \\
\text { distance }(\mathrm{m})\end{array}$ & $\begin{array}{c}\text { Scaled } \\
\text { distance }\left(\mathrm{m} / \mathrm{kg}^{1 / 3}\right)\end{array}$ & $\begin{array}{c}\text { Explosive } \\
\text { mass }(\mathrm{g})\end{array}$ \\
\hline NRC-1 & $1 \mathrm{E}$ & $2000 \times 1000 \times 100$ & 1.34 & 3 & 3.0 & 1007 \\
\hline NRC-2 & $1 \mathrm{E}$ & $2000 \times 1000 \times 100$ & 1.34 & 3 & 1.5 & 8139 \\
\hline NRC-3 & $1 \mathrm{~F}$ & $2000 \times 1000 \times 100$ & 1.34 & 1.4 & 0.93 & 3440 \\
\hline NRC-4 & $1 \mathrm{E}$ & $2000 \times 1000 \times 100$ & 1.34 & 1.5 & 0.75 & 8213 \\
\hline
\end{tabular}

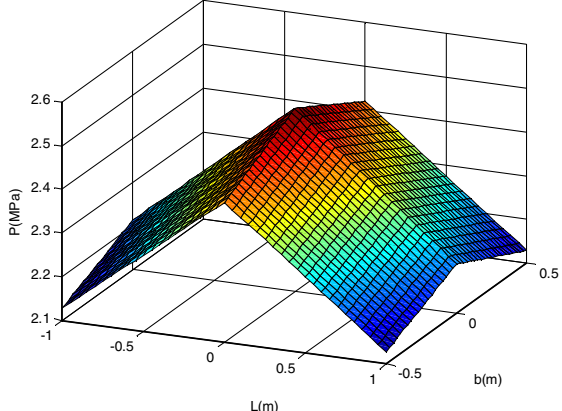

Fig. 5. A typical three-dimensional peak pressure distribution of the square RC slab.

code such as TM5 [9]. In this paper, the pressure is chose by TM5 empirical equation as a function of the scaled distance. A typical peak pressure $P(x, y)$ distribution on a square slab is shown in Fig. 5.

As shown in Fig. 4(a), the virtual rotation at the ends is $\theta$, and the external virtual work done by the uniform load $\bar{P}$ is

$$
\begin{aligned}
W_{e} & =4 \theta \int_{0}^{L / 2} \int_{0}^{L /(2 a)} \bar{P}\left(\frac{L}{2}-x\right) d x d y \\
& =4 \theta \bar{P} \int_{0}^{L / 2} \int_{0}^{L /(2 a)}\left(\frac{L}{2}-x\right) d x d y \\
& =4 \theta \bar{P} \frac{L^{3}}{16 a}
\end{aligned}
$$

On the other hand, as shown in Fig. 4(b), the virtual work done by the blast pressure wave $P(x, y)$ is

$$
\begin{aligned}
W_{P} & =4 \theta \int_{0}^{L / 2} \int_{0}^{L /(2 a)} P(x, y)\left(\frac{L}{2}-x\right) d x d y \\
& =4 \theta \frac{L^{3}}{a}\left[-P_{s 1} \frac{1}{32}+P_{s 2} \frac{1}{16}+P_{s 3} \frac{7}{96}-P_{s 4} \frac{1}{24}\right]
\end{aligned}
$$

Using the principle of virtual work and equating Eqs. (5) and (6), the uniform peak blast pressure, $\bar{P}$, is given by

$$
\begin{aligned}
W_{e} & =4 \theta \bar{P} \frac{L^{3}}{16 a} \\
& =4 \theta \frac{L^{3}}{a}\left[-P_{s 1} \frac{1}{32}+P_{s 2} \frac{1}{16}+P_{s 3} \frac{7}{96}-P_{s 4} \frac{1}{24}\right] \\
& =W_{P}
\end{aligned}
$$

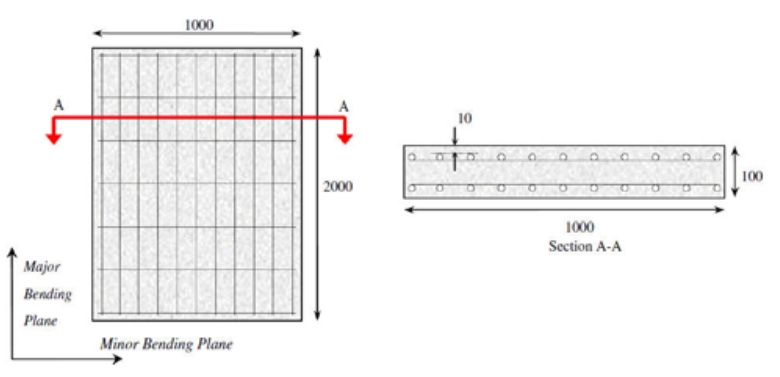

Fig. 6. Geometry of the rectangle RC slab (in mm).

$$
\bar{P}=\left[-P_{s 1} \frac{1}{2}+P_{s 2}+P_{s 3} \frac{7}{6}-P_{s 4} \frac{2}{3}\right]
$$

It is found from Eqs. (8) that the peak equivalent uniform blast pressure has no relationship with the span length to its slab width ratio $a$, and only influence by peak pressures of the four characteristic points in Fig. 5.

After the peak pressure of the equivalent blast pressure is got by above producer, the center blast load impulse is chose as the equivalent blast load impulse $[9,11]$. The load duration $t_{d}$ can be computed as

$$
t_{d}=\frac{2 I_{s 1}}{\bar{P}}
$$

where $I_{s 1}$ is the center blast load impulse, and $\bar{P}$ is the peak equivalent uniform blast pressure computed by Eqs. (8) for rectangle reinforced concrete slabs.

\section{Validation using experimental data}

To test the utility of the equivalent blast pressure method of SDOF model, the predictions were compared with maximum displacement data from blast testing results on one-way fixed supported $2 \mathrm{~m}$ long rectangle slabs by $\mathrm{Wu}$ $C$ [7]. The failure mode is the same with simple fixed slabs on the assumption that the slabs will be fail in the center line in flexure.

Details of the rectangle slab and other test data can be found in $\mathrm{Wu} \mathrm{C} \mathrm{[7].} \mathrm{Dimensions} \mathrm{of} \mathrm{the} \mathrm{slab} \mathrm{are} \mathrm{given} \mathrm{in}$ Fig. 6. These specimens were constructed with a $12 \mathrm{~mm}$ diameter mesh that was spaced in distance of $100 \mathrm{~mm}$ from each other in the major bending plane $(\rho=1.34 \%)$ and in distance of $200 \mathrm{~mm}$ from each other in the minor plane $(\rho=0.74 \%)$ where $\rho$ is reinforcement ratio. The thickness of the concrete cover was $10 \mathrm{~mm}$. The concrete had a cylinder compressive strength of $39.5 \mathrm{MPa}$, tensile 
Table 2. Max deflection compared with experiments of rectangle slabs.

\begin{tabular}{|c|c|c|c|c|c|}
\hline \multirow[b]{2}{*}{$\begin{array}{l}\text { Blast } \\
\text { test }\end{array}$} & \multirow{2}{*}{$\begin{array}{c}\text { Experiment } \\
\text { results } \\
\\
\text { Max } \\
\text { central } \\
\text { deflection } \\
(\mathrm{mm}) \\
\end{array}$} & \multicolumn{3}{|c|}{ Equivalent SDOF results } & \multirow[b]{2}{*}{$\begin{array}{c}\text { Prediction } \\
\text { error }(\%)\end{array}$} \\
\hline & & $\begin{array}{c}\text { Equivalent } \\
\text { uniform } \\
\text { peak } \\
\text { pressure } \\
(\mathrm{MPa})\end{array}$ & $\begin{array}{l}\text { Load } \\
\text { duration } \\
(\mathrm{ms})\end{array}$ & $\begin{array}{c}\text { Max } \\
\text { Central } \\
\text { deflection } \\
(\mathrm{mm})\end{array}$ & \\
\hline NRC-1 & 1.8 & 0.311 & 1.44 & 2.02 & 12 \\
\hline NRC-2 & 10.5 & 2.358 & 0.88 & 10.51 & 0.1 \\
\hline NRC-3 & 13.9 & 7.388 & 0.35 & 15.09 & 8.5 \\
\hline NRC-4 & 38.9 & 13.455 & 0.32 & 37.69 & -3.1 \\
\hline
\end{tabular}

strength of $8.2 \mathrm{MPa}$ and Young's modulus of $28.3 \mathrm{GPa}$. The reinforcement was of yield strength $600 \mathrm{MPa}$ and Young's modulus $200 \mathrm{GPa}$. The experimental test program is summarized in Table 1. The explosive charge was suspended above the center of the slab as described in [7].

The comparisons of experiments and equivalent SDOF results of the rectangle slab are shown in Table 2 . The equivalent uniform peak pressure and load duration are also listed in the table. One can found that based on Eqs. (8) and (9), the equivalent uniform peak pressures also increase and load duration decrease a litter more with reducing of the scaled distance. The equivalent SDOF results accurately predicted maximum displacement responses in all tests.

\section{Conclusions}

A new effective model for calculation of the equivalent uniform blast load for non-uniform blast load such as close-in explosion of a one-way square and rectangle reinforced concrete slab is proposed in this paper. A theoretical formula for peak equivalent uniform blast load is proposed with respect of peak pressures of the four characteristic points of the slab.

Based on the new effective model of blast pressure and equivalent SDOF method, the response of the slab is computed for different RC slabs under non-uniform blast load. A comparison between the measured and analytical responses was made and the largest difference was only $16 \%$, indicating that the new equivalent SDOF model can accurately predict the response of a square and rectangle $\mathrm{RC}$ slabs to blast loads.

However, unlike the finite element analysis that divides a member into three dimensional solid elements, the new equivalent SDOF model based on the conventional SDOF method with one key point of the slab such as center of the slab. Far fewer elements are used in the new equivalent SDOF model than elements in the finite element model, leading to a substantial reduction in the computational effort. Conventional SDOF analysis is straightforward and suitable for use in a design office but the results are based on the center blast pressure history of the slab and it can be substantially conservative with much higher of the results. The new equivalent SDOF model can capture many of the important features of a finite element analysis, provides accurate results, is computationally efficient and is ideally suited for slab design and blast assessment.

\section{References}

1. Xu K, Lu Y. Numerical simulation study of spallation in reinforced concrete plates subjected to blast loading. Comput Struct, 2006, 84:431-438.

2. Zhou XQ, Hao H, Deeks AJ. Modeling dynamic damage of concrete slab under blast loading. In: Hao $\mathrm{H}$, Lok TS, Lu GX, editors. Proceeding of the 6th AsiaPacific Conference on Shock and Impact Loads on StructuStructures, December, Perth, WA, Australia; 2005. p. 703-10. ISBN: 981-05-3550-3.

3. Biggs JM. Introduction to Structural Dynamics. McGraw-Hill, 1964.

4. Mays GC, Smith PD. Blast effects on buildings-design of buildings to optimize resistance to blast loading. London: Thomas Telford, 1995.

5. Lu B, Silva PF. Improving the blast resistance capacity of RC slabs with innovative composite materials. Compos Part B-Eng, 2007, 38, 523-534.

6. Silva PF, Lu B. Blast Resistance Capacity of Reinforced Concrete Slabs. J Struct Eng-ASCE, 2009, 135: 708-716.

7. Wu C, Oehlers DJ, Rebentrost M, Burman N, Whittaker AS. Blast testing of ultrahigh performance fiber concrete slabs and FRP retrofitted RC slabs. Eng Struct, 2009, 31:2060-2069.

8. Krauthammer T. Blast-resistant structural concrete and steel connections. Int J Impact Eng, 1999, 22: 887-910.

9. TM5-1300. Structures to resist the effect of accidental explosions. US Department of the Army, Navy and Air Force Technical Manual; 1990.

10. PDC-TR 06-01 Rev 1, Methodology manual for the Single degree of freedom blast effects design spreadsheets, US Army Corps of Engineers, 2008.

11. UFC 3-340-02 (TM5-1300), Structures to resist the effects of accidental explosions, 2008. 
12. Livermore Software Technology Corporation (LSTC). LS-DYNA. Version 971 Manual. Livermore (CA, USA). 2007.

13. AUTODYN. Theory Manual. Century Dynamics, 2006.

14. Krauthammer T, Shahriar S, Shanaa HM. Response of reinforced concrete elements to severe impulsive loads. J Struct Eng, 1990, 116:1061-79.
15. Low HY, Hao H. Reliability analysis of direct shear and flexural failure modes of RC slabs under explosive loading. Eng Struct, 2002, 24: 189-98.

16. Krauthammer T. Workshop on structural concrete slabs under impulsive loads. Proceedings of the Third International Conference on Structures under Shock and Impact, Spain: Madrid, 1994:99-106. 